\title{
CLASSIFICAÇÃO DAS PRÁTICAS DE ENFERMAGEM EM SAÚDE COLETIVA NO BRASIL
}

CLASSIFICATION OF NURSING PRACTICES IN COLLECTIVE HEALTH IN BRAZIL.

\author{
Maria José Morais Antunes ${ }^{1}$ \\ Isilia Aparecida Silva ${ }^{2}$ \\ Emiko Yoshikawa Egry ${ }^{3}$ \\ Roseni Rosângela Chompré ${ }^{4}$
}

Em 1991, o Conselho Internacional de Enfermeiras (CIE) iniciou um processo no qual a questão central girava em torno do estabelecimento de um sistema de comunicação (local, regional e internacional) a partir de nomenclaturas específicas que dessem conta de descrever as mais distintas práticas da enfermagem no mundo. Desencadeou este processo a constatação de que o trabalho da enfermagem, na enorme gama de ações construídas desde sua gênese - na moderna acepção, continua invisibilizada ainda, decorrente, entre outras causas, da inexistência de dados que expressem - no coletivo e no individual - claramente os Objetos de trabalho com os quais se defronta.

Albergando esta preocupação e sustentada na necessidade real de se apreender as distintas práticas de enfermagem em saúde coletiva no cenário brasileiro, a Associação Brasileira de Enfermagem, enquanto uma entidade profissional que tem "o compromisso ético, político e técnico de propor e defender políticas e programas que visem a melhoria da qualidade de vida da população ..." (ABEn, 1994) constituiu, em 1996, o Projeto de Classificação das Práticas de Enfermagem em Saúde Coletiva no Brasil, cujos pressupostos e propósitos centrais serão a seguir descritos.

Consideradas a historicidade e a dinâmica das transformações no setor saúde, decorrentes das transformações sociais mais amplas (modo de produção da sociedade brasileira), o presente projeto tem como Objetivo Geral contribuir para a transformação das práticas de enfermagem em saúde coletiva no Brasil, tendo por referência os pressupostos da Reforma Sanitária

${ }^{1}$ Enfermeira. Mestre em Enfermagem pela UFMG. Doutoranda da EEUSP. Diretora de Assuntos Profissionais da ABEn, gestão 95/98. Coordenadora Geral do Projeto.

2 Enfermeira. Mestra em Enfermagem pela EEUSP. Doutora em Enfermagem pela EEUSP. Professor Doutor do Departamento de Enfermagem Materno-Infantil e Psiquiátrica da EEUSP. Diretora do CEPEN (Centro de Estudos e Pesquisa em Enfermagem da ABEn), gestão 95/98. Coordenadora Geral Adjunta do Projeto.

${ }^{3}$ Enfermeira. Mestra em Enfermagem pela EEUSP. Doutora em Saúde Pública pela FSP-USP. Livre-docente em Enfermagem em Saúde Coletiva pela EEUSP. Professora Titular em Enfermagem em Saúde Coletiva da EEUSP. Coordenadora Técnica do Projeto.

4 Enfermeira. Mestra em Veterinária (Área de Epidemiologia) pela UFMG. Doutora em Enfermagem pela EEUSP. Professora Adjunta da.Escola de Enfermagem da UFMG. Consultora da Fundação W.K. Kellogg para a América Latina e Caribe. Coordenadora de Avaliação do Projeto. 
Brasileira, os perfis de saúde-doença da população e a inscrição constitutiva da enfermagem no processo de produção de saúde.

O alcance deste objetivo hercúleo, para além da requerida estratégia operacional efetiva e do rigor metodológico, apoia-se na premissa de que todo o conhecimento verdadeiramente impactante no sentido de superação das contradições da prática deve existir e ser produzido num contexto de compartida e reflexão conjunta do saber. Assim, o desenvolvimento do Projeto levará em conta tanto o processo quanto o produto, principalmente no que se refere à qualificação e requalificação da força de trabalho em enfermagem, privilegiandose neste caso o saber instrumental.

Os propósitos centrais do projeto são: a) estabelecer mecanismos de cooperação para a classificação da prática de enfermagem em saúde coletiva no País; b) revisitar as práticas de enfermagem em saúde coletiva no País, contextualizadas no processo de produção em saúde, diante da implantação do Sistema Único de Saúde; c) construir um sistema de informação das práticas de enfermagem em saúde coletiva que permita a sua classificação, troca de experiências e interlocução nos níveis nacional e internacional.

Subordinados a estes propósitos centrais, foram constituídos os objetivos especificos que se encontram descritos no Projeto.

O marco teórico-metodológico adotado configurou as categorias analíticas momento investigativo - e as categorias interpretativas - momento interventivo apresentando-se neste estudo tal como se segue: trabalho (elementos constitutivos do processo de trabalho, formas de organização, infra-estrutura e recursos humanos); força de trabalho (composição, estruturação, organização, programas e estratégias de operacionalização e sistemas de qualificação e requalificação); educação (organização interna e articulação com as instituições de ensino e pesquisa); modelo assistencial (propostas teóricas de concretização e obstáculos para a implantação do SUS); enfermagem (teorias e marcos teóricos que embasam a prática, concretização da prática, obstáculos para a expansão das ações de enfermagem, parâmetros de avaliação da qualidade do trabalho e indicadores de avaliação e produção e reprodução de conhecimentos); e perfis epidemiológicos da população adscrita no Distrito Sanitário (processos de produção e reprodução social, indicadores demográficos, perfis de morbidade e mortalidade, mapeamento de grupos homogêneos).

O desenvolvimento do presente projeto contará com o apoio financeiro da Fundação W. K. Kellogg, assentado em base operativa das ABEns-seção, compartidas com a Academia e o Serviço, monitorados por supervisão regional (Núcleos A, B, C, D, E e F) e coordenados pela equipe de Coordenação Geral do Projeto, com cronograma inicial de três anos, de 1997 ao ano 2000. 